AN EMPIRICAL ANALYSIS OF INTERTEMPORAL ASSET PRICING MODELS WITH TRANSACTION COSTS AND HABIT PERSISTENCE

by

Wessel MARQUERING Marno VERBEEK

$\simeq$

Econometrics

Center for Economic Studies

Discussion Paper Series DPS 98.24

$\Sigma$

$\supset$

$\llbracket$ 


\title{
An Empirical Analysis of Intertemporal Asset Pricing Models with Transaction Costs and Habit Persistence*
}

\author{
Wessel Marquering \\ K.U. Leuven
}

\author{
Marno Verbeek \\ K.U. Leuven and Tilburg University
}

December 4, 1998

\begin{abstract}
In intertemporal asset pricing models, transaction costs are usually neglected. In this paper we explicitly incorporate transaction costs in these models and analyze to what extent this extension is helpful in explaining the cross-section of expected returns. An empirical analysis using CRSP data on size-based portfolios examines the role of the transaction costs and shows that incorporating such costs in the consumption-based model with power utility does not yield satisfactory results. However, the introduction of habit persistence substantially improves the model. We find rather strong evidence of habit persistence in monthly consumption data. The plots of the models' pricing errors indicate that the asset pricing model with transaction costs and habit persistence does explain the cross-sectional variation in the portfolio returns quite accurately.
\end{abstract}

${ }^{*}$ Helpful comments by Peter de Goeij, Frans de Roon, Ramdan Dridi, Georges Hübner, and Frans Spinnewyn are gratefuly acknowledged. Address all correspondence to: Wessel Marquering, Center for Economic Studies, K.U. Leuven, Naamsestraat 69, 3000 Leuven, Belgium. Tel.: +32-16-326849. Fax: +32-16-326796. E-mail: Wessel.Marquering@econ.kuleuven.ac.be. 


\section{Introduction}

Transaction costs can play an important role in explaining the behavior of the returns of assets. While in most asset pricing models market frictions are assumed to be negligible, there is empirical evidence against this assumption, mainly within a CAPM or APT setup (see, for example, Schultz (1983), and Amihud and Mendelson (1986, 1989)). Most intertemporal consumption-based asset pricing models without market frictions are empirically rejected (see Hansen and Singleton (1982), and Singleton (1990, 1994)). In a recent study, Cochrane (1996) obtains an estimate for the relative risk aversion coefficient using a CRRA consumption-based model without transaction costs that is extremely high, a result which reflects the equity premium puzzle. Moreover, the implied pricing errors for ten size-based portfolios are relatively high. Neglecting market frictions can be an explanation for the frequent rejections of the intertemporal models and it may provide an answer to the equity premium puzzle. Because transaction costs will make investors trade less frequently, investors are less able to hedge against consumption uncertainty, such that the presence of such market imperfections increases consumption volatility. The higher the transaction costs, the higher is the standard deviation of consumption growth.

In this paper, we incorporate transaction costs in intertemporal consumption-based asset pricing models. For intertemporal asset pricing models empirical results incorporating market frictions are scarce. Among these are Fisher (1994), He and Modest (1995), Heaton and Lucas (1996), and Luttmer (1996), where only two of these studies actually estimate a model. The remaining two studies are based on the Hansen and Jagannathan (1991) volatility bounds. While most of the attention has been given to theoretical impact of transaction costs, Fisher (1994) is one of the few who combines intertemporal asset pricing models with transaction costs in an empirical way. He finds that, using a market portfolio and a riskfree rate, the estimates of the transaction costs parameter are relatively high and significantly different from zero. In this paper we extend the work of Fisher in several directions. First of all, we use returns on ten size-based portfolios to analyze to what extent transaction costs do help explaining the cross-section of expected returns. Second, we use monthly rather than annual data, and third, following Ferson and Constantinides (1991), Cochrane and Hansen (1992), and Heaton (1995) we also consider a time-nonseparable specification of utility. The idea behind this extension is that consumers get used to high levels of consumption and desire high consumption in period $t$ when consumption in period $t-1$ was high. A positive effect of the consumption level of period $t-1$ on the 
marginal utility at time $t$ is called habit persistence. In this paper, we will empirically examine the combined effect of habit persistence and transaction costs using US asset market data. Our main issue is to analyze the question whether ignoring market frictions and/or time-nonseparability of utility can provide an explanation for the frequent rejections of intertemporal asset pricing models and corresponding the equity premium puzzle. A possible explanation for the equity premium puzzle is that investors want to be compensated for relatively high transaction costs on the stock market. Standard asset pricing models do not account for these costs.

The remainder of this paper is organized as follows. Section 2 presents the utility maximization problem with transaction costs in the stock market. The resulting asset pricing model is a generalization of the CRRA consumption-based asset pricing model as examined in Hansen and Singleton (1982) and many other articles. The method of estimation is explained in Section 3, while the empirical results using monthly US stock market data for 1959-1993 are presented in Section 4. Section 5 extends the model to cover a time-nonseparable utility function with habit persistence. Following Cochrane (1996), the different models are evaluated statistically, in terms of specification tests, and economically, in terms of pricing errors. We conclude in Section 6 by summarizing the main results.

\section{The Model}

In this section we derive an intertemporal equilibrium model for asset prices, incorporating transaction costs in the stock market. This model is similar to the one in Fisher (1994), albeit that the specification discussed here is slightly more general. Our focus is an empirical analysis using monthly data for ten risky portfolios and a riskless asset, where Fisher only uses one aggregate risky asset, so that we can analyze to what extent transactions costs are helpful in explaining the cross-sectional variation in returns. In order not to complicate the notation, we shall start by considering one risky asset only. Later we will show how the model can readily be extended to multiple risky assets.

We consider a discrete time economy with a single consumption good and a large number of infinitely lived agents. The representative agent, which is assumed to summarize the behavior of the population ${ }^{1}$, wishes to maximize his expected utility under a dynamic

\footnotetext{
${ }^{1}$ Under a set of aggregation conditions given in Rubinstein (1974), the representative agent approach is a valid method to summarize the behaviour of all the (heterogenous) agents in the economy.
} 
budget constraint, that is he solves

$$
\max _{c_{t}, s_{t+1}, b_{t+1}} E_{t}\left\{\sum_{j=0}^{\infty} \delta^{j} u\left(c_{t+j}\right)\right\}, \quad 0<\delta<1
$$

subject to

$$
c_{t}+p_{t} s_{t+1}+p_{t}^{b} b_{t+1}+\kappa\left(s_{t+1}, s_{t}\right)=\left(p_{t}+d_{t}\right) s_{t}+b_{t}+y_{t},
$$

where $E_{t}\{$.$\} denotes the expectation operator, conditional on information available at$ time $t, u($.$) is the one-period utility function in terms of consumption c_{t}$, and $\delta$ is a time preference parameter. The amounts of stocks and bonds, which are riskfree claims to one unit of consumption at time $t+1$, are denoted by $s_{t}$ and $b_{t}$, with prices $p_{t}$ and $p_{t}^{b}$, respectively. Dividends per stock are denoted by $d_{t}$, while $y_{t}$ denotes other income (for example labor income). Finally, the function $\kappa($.$) denotes the transaction costs in the$ stock market. The agent maximizes utility with respect to the consumption choice, stock holdings, and bond holdings. Each period the agent receives income from investing in risky stocks and riskless bonds and other income (the RHS of (2)). The total income is used to consume, invest in assets and to pay transaction costs on stocks (the LHS of (2)). It is assumed that there are no transaction costs in the bond market. Below, the assumption of a time separable utility function will be relaxed.

We will discuss a transaction costs specification, which is equivalent to Fisher's (1994) approach. The trading costs in the stock market are assumed to be a linear function of the value of the trade:

$$
\kappa\left(s_{t+1}, s_{t}\right)=\left(s_{t+1}-s_{t}\right)\left(p_{t}^{a s k}-p_{t}\right)+s_{t} \Omega_{t}\left(p_{t}^{a s k}-p_{t}^{b i d}\right),
$$

with $p_{t}^{a s k}\left(\geq p_{t}\right)$ the ask price and $p_{t}^{b i d}\left(\leq p_{t}\right)$ the bid price of the stock. New stocks must be purchased at the ask price, while stocks must be sold at the bid price. $\Omega_{t}$ denotes the proportion of the agent's portfolio that is liquidated. Following Fisher, we will treat $\Omega_{t}$ as given and, in the empirical application, approximate it by a measure of asset turnover. Recall that the portfolio of the representative agent is the aggregate of the individual portfolios, which will be partly liquidated each period. The introduction of $\Omega_{t}$, allows that in general the transaction costs do not just depend upon the net aggregate change in the asset position, but also upon the volume of the transactions that take place at a disaggragate level.

The introduction of the bid-ask spread $p_{t}^{a s k}-p_{t}^{\text {bid }}$ and asset turnover into the agent's optimization problem is expected to lead to a higher expected return on risky assets relative 
to the case of a zero bid-ask spread. The specification in (3) has an intuitive attractive interpretation, as the transaction costs on equity depend on the increment in stocks and the number of stocks that are liquidated. Hansen et al. (1995), He and Modest (1995), and Luttmer (1996) use intertemporal asset pricing models with transaction costs in which the investor must sell his whole portfolio each period. The advantage of the approach in this paper is that partial selling is allowed, which is a more realistic assumption.

The bid-ask spread typically consists of the costs of gathering information, taxes, brokerage fees, the buy and sell quotations, and market impact. For empirical purposes it is convenient to work with proportional transaction costs with respect to the ask and bid price. This proportionality implies: ${ }^{2}$

$$
\begin{aligned}
p_{t}^{a s k} & =p_{t}(1+\alpha) \\
p_{t}^{b i d} & =p_{t}(1-\alpha),
\end{aligned}
$$

where $\alpha(>0)$ denotes the proportional transaction cost (i.e. the bandwidth of the bid-ask spread). Now, equation (3) reduces to:

$$
\kappa\left(s_{t+1}, s_{t}\right)=\alpha p_{t}\left(s_{t+1}-s_{t}\right)+2 \alpha p_{t} s_{t} \Omega_{t} .
$$

It is a complicated task to solve the model explicitly for the decision variables. Fortunately, we only need the first order conditions to estimate the unknown parameters. These first order conditions can be found by solving the dynamic optimization problem. When the agent is not liquidity constrained, and chooses consumption, stock and bond holdings optimally, it is quite straightforward to show that

$$
\begin{gathered}
E_{t}\left\{\delta \frac{u^{\prime}\left(c_{t+1}\right)}{u^{\prime}\left(c_{t}\right)} \frac{p_{t+1}+d_{t+1}+\alpha\left(1-2 \Omega_{t+1}\right) p_{t+1}}{p_{t}(1+\alpha)}\right\}=1 . \\
E_{t}\left\{\delta \frac{u^{\prime}\left(c_{t+1}\right)}{u^{\prime}\left(c_{t}\right)} \frac{1}{p_{t}^{b}}\right\}=1 .
\end{gathered}
$$

For the individual investor, the marginal transaction costs are not defined at $s_{t+1}=s_{t}$. We could resolve this by defining the derivative in this point by 0 or by defining upper and lower limits for the marginal transaction costs around $s_{t+1}=s_{t} \cdot{ }^{3}$ The nondifferentiability

\footnotetext{
${ }^{2}$ Experiments with a similar specification in which the ask price equals $p_{t}(1+\alpha)$ and the bid price satisfies $p_{t} /(1+\alpha)$, yielded virtually identical empirical results.

${ }^{3}$ An alternative solution to this nondifferentiability is to assume a quadratic transaction cost function around $s_{t+1}=s_{t}$ (see, for example, Heaton and Lucas (1996)).
} 
is automatically circumvented as we assume, like Fisher (1994), that $\Omega_{t}$ is exogenously given.

Note that for $\alpha=0$, (6) reduces to the model used in Hansen and Singleton (1982) and Singleton $(1990,1994)$, i.e. a CRRA consumption-based asset pricing model without transaction costs. Compared to the standard first order conditions, the marginal transaction costs play a role in these expressions. The interpretation of equation (6) is that buying an additional unit of equity at time $t$ has a marginal cost of $p_{t}(1+\alpha)$, and yields a marginal revenue in the next period of $p_{t+1}+d_{t+1}+\alpha\left(1-2 \Omega_{t+1}\right) p_{t+1}$. Note that the effects of stock market transaction costs on the bond market are only possible through changes in (the distribution of) the intertemporal marginal rate of substitution $\delta u^{\prime}\left(c_{t+1}\right) / u^{\prime}\left(c_{t}\right)$.

In order to examine whether the model can explain the cross-sectional variation of asset returns we will estimate the model for 10 portfolio deciles, ranked according to their size (capitalization-based or size-based portfolios) as will be described in Section 4.1. To do this we have to extend the model's set-up to cover multiple risky assets with multiple sources of transaction costs, which is relatively straightforward under the following assumptions.

Assume that the investor can choose freely between a variety of risky (portfolios of) assets $i=1, \ldots, n$ (here $n=10$ ), where $n$ is constant over time. Denote the quantities of these assets by $s_{t}^{i}$. The most important assumption now is that the transaction component for asset $i, \kappa^{i}$, is independent of transactions in any of the other assets, $s^{1}, \ldots, s^{i-1}, s^{i+1}, \ldots, s^{n}$, for all time periods (no "package deals"). To economize on notation, we assume that the specific transaction specification is the same for all assets, with the same $\alpha$ 's. Given data limitations, it will be assumed that the turnover rates are the same for all (risky) portfolios.

Denote $p_{t}^{i}, d_{t}^{i}, \kappa^{i}$, for the price, the dividend and the transaction costs of asset $i$. Then we can rewrite the dynamic optimization problem as:

$$
\max _{c_{t}, b_{t+1}, s_{t+1}^{1}, \ldots, s_{t+1}^{n}} E_{t}\left\{\sum_{j=0}^{\infty} \delta^{j} u\left(c_{t+j}\right)\right\}, \quad 0<\delta<1
$$

subject to

$$
c_{t}+\sum_{i=1}^{n} p_{t}^{i} s_{t+1}^{i}+p_{t}^{b} b_{t+1}+\sum_{i=1}^{n} \kappa^{i}\left(s_{t+1}^{i}, s_{t}^{i}\right)=\sum_{i=1}^{n}\left(p_{t}^{i}+d_{t}^{i}\right) s_{t}^{i}+b_{t}+y_{t}
$$

Solving this optimization problem leads to modified first order conditions (c.f. (6)). Using a generalized version of equations (3) and $(4)^{4}$ and using the assumption that the alpha's

\footnotetext{
${ }^{4}$ Note that the generalized versions of these equations satisfy:

$$
\kappa^{i}\left(s_{t+1}^{i}, s_{t}^{i}\right)=\left(s_{t+1}^{i}-s_{t}^{i}\right)\left(p_{t}^{i, a s k}-p_{t}^{i}\right)+s_{t}^{i} \Omega_{t}^{i}\left(p_{t}^{i, a s k}-p_{t}^{i, b i d}\right),
$$
}


and the turnover rates are the same for all risky portfolios, we may write ${ }^{5}$

$$
E_{t}\left\{\delta \frac{u^{\prime}\left(c_{t+1}\right)}{u^{\prime}\left(c_{t}\right)}\left[\frac{1}{1+\alpha} r_{t+1}^{i}+\frac{\alpha}{1+\alpha}\left(1-2 \Omega_{t+1}\right) \frac{p_{t+1}^{i}}{p_{t}^{i}}\right]\right\}=1, \quad i=1, \ldots, n .
$$

In (10) $r_{t+1}^{i}=\left(p_{t+1}^{i}+d_{t+1}^{i}\right) / p_{t}^{i}$ represents the gross return on portfolio $i$, while $p_{t+1}^{i} / p_{t}^{i}$ is the ex dividend return. The expression in terms of excess returns becomes

$$
E_{t}\left\{\delta \frac{u^{\prime}\left(c_{t+1}\right)}{u^{\prime}\left(c_{t}\right)}\left[\left(r_{t+1}^{i}-r_{t+1}^{f}\right)+\left(\alpha-2 \alpha \Omega_{t+1}\right) \frac{p_{t+1}^{i}}{p_{t}^{i}}\right]-\alpha\right\}=0, \quad i=1, \ldots, n .
$$

Assuming a parametric form for (marginal) utility, this model will be estimated using monthly US asset market data. We will compare the results with those obtained from a model without transaction costs and test whether the transaction component has a significance influence. To compare different specifications we will use overidentifying restrictions tests and plots of pricing errors as in Cochrane (1996). Before describing the data and the estimation results, we will first discuss how we estimate the model parameters and evaluate the models' empirical performance.

\section{Estimation and Evaluation}

In this section we describe how the parameters of the model with transaction costs can be estimated by a one step and iterated generalized method of moments (GMM) procedure. In Subsection 3.1, we shall, starting from Hansen's (1982) two-step estimator, explain iterated GMM, which is likely to have better small sample properties. Next, we will argue that in some cases a one-step GMM estimator, where the weighting matrix equals the identity matrix, may be preferred, in particular if the estimated model is evaluated in terms of its implied pricing errors. We also describe how the model can be evaluated statistically using overidentifying restriction tests. How average pricing errors can be computed from the parameter estimates and the data is discussed in Subsection 3.2.

\footnotetext{
$p_{t}^{i, a s k}=p_{t}^{i}\left(1+\alpha_{i}\right)$$$
p_{t}^{i, b i d}=p_{t}^{i}\left(1-\alpha_{i}\right), \quad i=1, \ldots, n .
$$

${ }^{5}$ Because we prefer working with stationary variables, the variables have been transformed into returns instead of prices and dividends.
} 


\subsection{Estimation method}

First, we convert the conditional moment conditions in (11) into unconditional moment conditions: ${ }^{6}$

$$
E\left\{\delta \frac{u^{\prime}\left(c_{t+1}\right)}{u^{\prime}\left(c_{t}\right)}\left[\left(r_{t+1}^{i}-r_{t+1}^{f}\right)+\left(\alpha-2 \alpha \Omega_{t+1}\right) \frac{p_{t+1}^{i}}{p_{t}^{i}}\right]-\alpha\right\}=0,
$$

We define the vector $\mathbf{g}(\boldsymbol{\beta})$ as the sample equivalent of (12), with $\boldsymbol{\beta}$ the vector of unknown parameters. Under the assumption that (12) is true, $\mathbf{g}(\boldsymbol{\beta})$ will be close to zero for large sample sizes $T$. The GMM estimator is found by minimizing a quadratic form in $\mathbf{g}(\boldsymbol{\beta})$, that is

$$
\hat{\boldsymbol{\beta}}_{G M M}=\operatorname{Arg} \min _{\boldsymbol{\beta}} \mathbf{g}(\boldsymbol{\beta})^{\prime} W \mathbf{g}(\boldsymbol{\beta}),
$$

where $W$ is a symmetric positive definite weighting matrix. ${ }^{7}$ Different weighting matrices lead to different, consistent, estimators for $\boldsymbol{\beta}$. Hansen (1982) shows how the "optimal" weighting matrix can be chosen so as to minimize the asymptotic covariance matrix of $\hat{\boldsymbol{\beta}}_{G M M}$ among this class of estimators. Usually, the number of moment conditions will exceed the number of parameters that is estimated, and it is possible to test the overidentifying restrictions by means of a Chi-squared test. Under the null hypothesis that (12) is correct, the minimized value of (13), which we denote as $J_{T}$, has an asymptotic $\chi^{2}$-distribution, with degrees of freedom equal to the difference between the number of moment conditions and the number of unknown parameters. This $J_{T}$ statistic can be used to test the overidentifying restrictions, that is to test whether we can statistically reject a given observable factor model against a nonspecific alternative (see Cochrane, 1996).

Because the optimal weighting matrix depends upon $\boldsymbol{\beta}$, Hansen's GMM estimator is a two-step estimator. A simple weighting matrix (for example the identity matrix) is used to obtain an initial consistent estimator for $\boldsymbol{\beta}$, which is then used in a second step to construct the optimal weighting matrix. In order to improve the small sample properties of the GMM estimator, Ferson and Foerster (1994) have suggested to use an iterated GMM procedure. In this case, the optimal weighting matrix is recomputed from the new estimate

\footnotetext{
${ }^{6}$ Obviously, a set of unconditional moment conditions can be derived for any instrument that is in the information set at time $t$. As we do not estimate conditional versions of the model, we abstract from this here.

${ }^{7}$ The objective of GMM in intertemporal asset pricing models is to minimize a weighted quadratic form of pricing errors to obtain estimates for the unknown parameters. This weighting matrix can be interpreted as a matrix indicating how much attention is paid to each of the moment conditions (or linear combinations of moment conditions).
} 
for $\boldsymbol{\beta}$, and this is iteratively repeated until convergence. This estimator has the same limit distribution as the optimal two-step estimator, but is, in general, more efficient in small samples.

A potential disadvantage is that both two-step GMM and iterated GMM may use weighting matrices that involve extremely large weights for particular (combinations of) moment conditions. These are the moment conditions that happen to be statistically accurate (in the sense of having a small sample variance), but not necessarily economically more interesting than the others. This problem has led Cochrane (1996) to suggest the use of a one-step estimator, using the identity matrix as the weighting matrix (denoted by $I) .{ }^{8}$ Using GMM with the identity matrix as weighting matrix (this particular matrix weights all moment conditions equally) is equivalent to minimizing the mean square of the pricing errors. "So if we compare models by pricing error plots, we know that each model will fit as well as possible along this dimension" (Cochrane, 1996). In view of the above arguments, we shall also apply first-stage GMM and consider the implied pricing errors. It will appear that two-step or iterated GMM may lead to very large pricing errors. As Cochrane, we feel that plotting pricing errors is a very useful tool to detect economically uninteresting models that are not rejected statistically.

Using a sub-optimal weighting matrix, like the identity matrix, requires one to adjust the formulae for the asymptotic distribution of the GMM estimator. Our one-step estimator is obtained from (13), when replacing $W$ by $I$, and has not the same limit distribution as the two-step or iterated GMM estimator. To calculate the correct standard errors and the overidentifying restrictions test statistic $J_{T}$, we use the formulas given in Hansen (1982) and Cochrane (1996).

\subsection{Pricing errors}

In this subsection we derive the predicted mean excess returns of the size-based portfolios, which can be plotted against the actual mean excess returns. These pricing error plots are a very useful diagnostic tool, especially in situations where the predictions of the mean portfolio returns are poor, but the overidentifying restrictions test does not indicate

\footnotetext{
${ }^{8}$ Another reason to prefer the one-step estimator is the following (see Cochrane, 1996): "one can not compare two $J_{T}$ statistics from two estimates with different weighting matrices. The statistics can only be compared when choosing the same weighting matrix. Two-step or iterated GMM chooses, in general, different weighting matrices for different estimations. A model can achieve a low $J_{T}$ by simply blowing up the covariance matrix of the moment conditions rather than improving the moment conditions."
} 
possible misspecifications (possibly due to high standard errors).

Let us consider the moment conditions in (12), i.e.

$$
E\left\{m_{t+1}\left[\left(r_{t+1}^{i}-r_{t+1}^{f}\right)+\left(\alpha-2 \alpha \Omega_{t+1}\right) \frac{p_{t+1}^{i}}{p_{t}^{i}}\right]-\alpha\right\}=0
$$

where $m_{t+1}$ denotes the stochastic discount factor, $\delta u^{\prime}\left(c_{t+1}\right) / u^{\prime}\left(c_{t}\right)$. In this stochastic discount factor model with transaction costs the predicted excess return can be found by decomposing (14). The model predicts that the expected excess return satisfies:

$$
E\left\{r_{t+1}^{i}-r_{t+1}^{f}\right\}=\frac{-\operatorname{Cov}\left\{m_{t+1}, r_{t+1}^{i}-r_{t+1}^{f}\right\}}{E\left\{m_{t+1}\right\}}-\frac{E\left\{m_{t+1}\left(\alpha-2 \alpha \Omega_{t+1}\right) \frac{p_{t+1}^{i}}{p_{t}^{i}}-\alpha\right\}}{E\left\{m_{t+1}\right\}},
$$

which can be estimated as

$$
\frac{-\frac{1}{T} \sum_{t} \hat{m}_{t+1}\left(r_{t+1}^{i, e}-\bar{r}^{i, e}\right)}{\frac{1}{T} \sum_{t} \hat{m}_{t+1}}-\hat{\alpha} \frac{\frac{1}{T} \sum_{t}\left(\hat{m}_{t+1}\left(1-2 \Omega_{t+1}\right) \frac{p_{t+1}^{i}}{p_{t}^{i}}-1\right)}{\frac{1}{T} \sum_{t} \hat{m}_{t+1}}
$$

where $r_{t+1}^{i, e}$ denotes the excess return on asset $\mathrm{i}\left(r_{t+1}^{i}\right)$ in excess of the risk free rate $\left(r_{t+1}^{f}\right)$, $\hat{m}_{t+1}$ denotes the stochastic discount factor evaluated in the estimated parameters, and $\bar{r}^{i, e}$ the sample mean of $r_{t}^{i, e}$. Thus (16) provides the average predicted excess return on asset $i$ according to the consumption-based asset pricing model with transaction costs.

The average excess return of asset $i$ in the sample period is simply computed as

$$
\frac{1}{T} \sum_{t}\left(r_{t+1}^{i}-r_{t+1}^{f}\right)
$$

such that the average pricing error in a model with transaction costs is given by the difference between the mean excess returns and the predicted mean excess returns. The pricing errors for the model without transaction costs can be computed from the above formulae using the restricted model estimates and setting $\hat{\alpha}$ to zero.

The next section presents the empirical results for the consumption-based asset pricing model with power utility using monthly US stock market data for 1959-1993. After introducing the data in Subsection 4.1, the model estimates and pricing errors are presented and discussed in Subsection 4.2. In Section 5, we consider the introduction of habit persistence in the utility function. 
Figure 1: Value of some portfolios of hypothetical investment of $\$ 100$ in 1959. Note that the value of the portfolio on the vertical axis has a log scale.

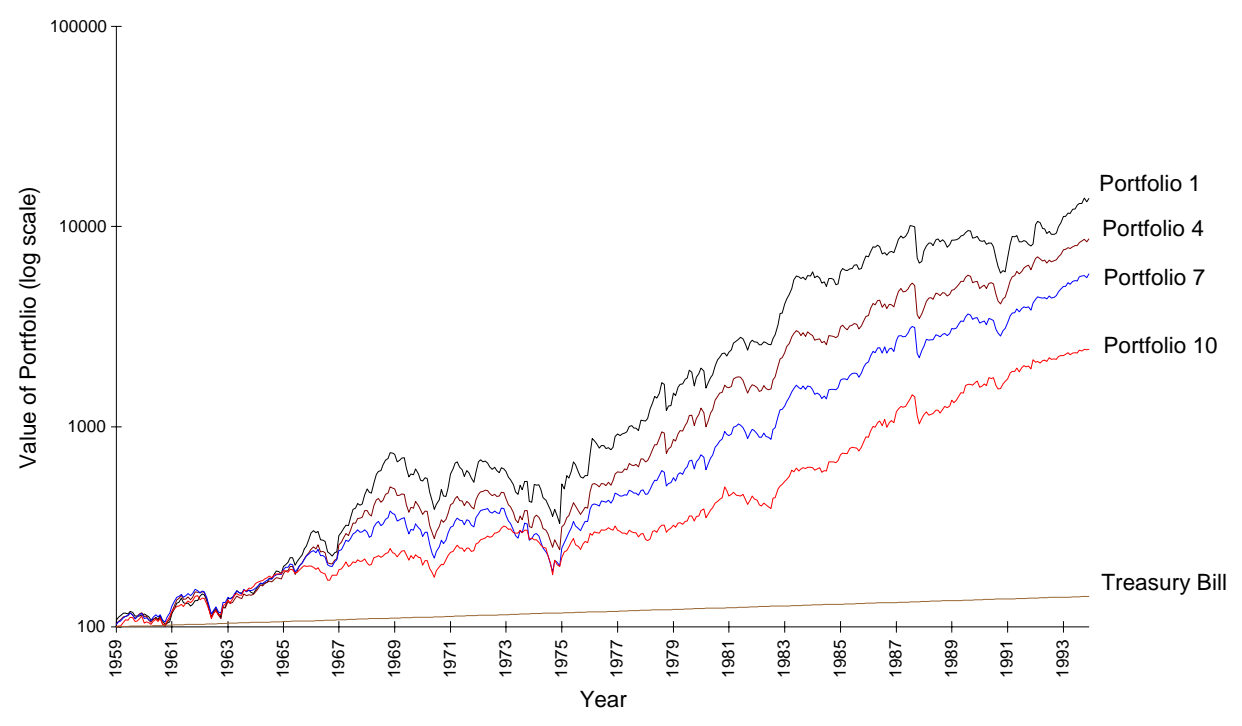

Figure 2: Monthly turnover rate, i.e. the ratio of the total number of shares traded and the total number of shares outstanding, from 1959 to 1993.

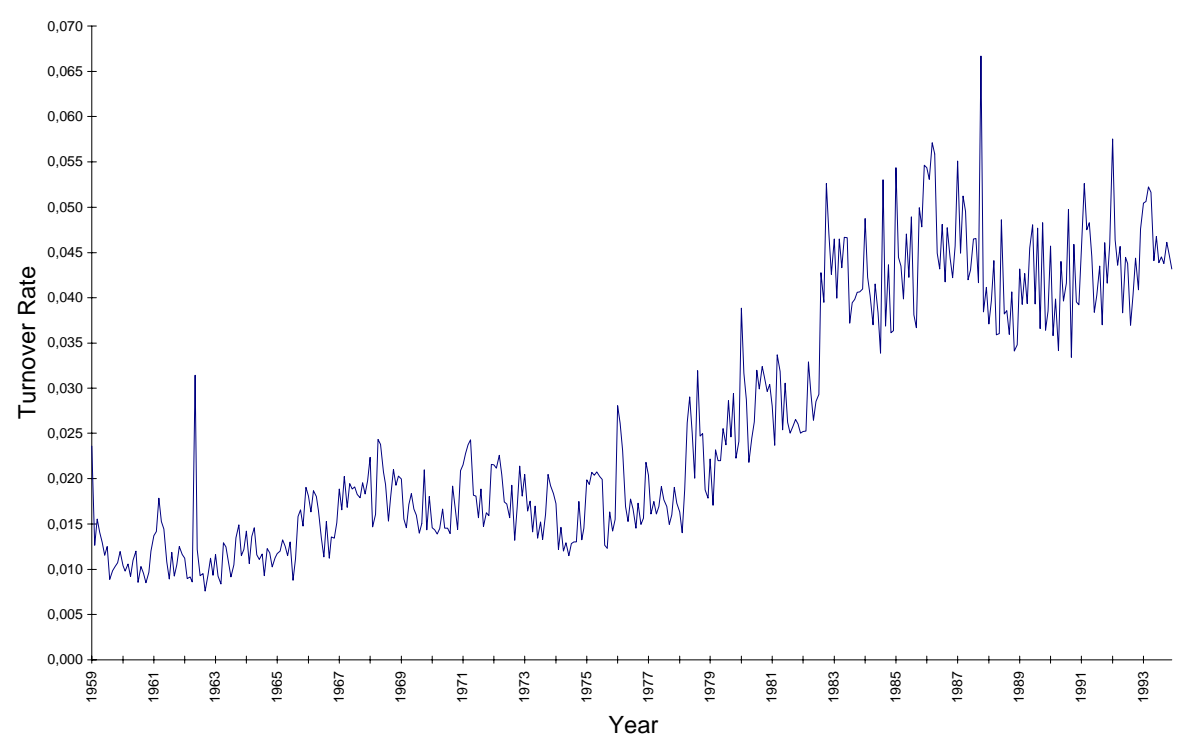




\section{Empirical Results}

\subsection{Data and stylized facts}

To estimate the intertemporal asset pricing models we use monthly returns data of ten size-based portfolios and a riskless asset for the period February 1959 to November 1993. Data on the ten risky portfolios are supplied by the Center for Research in Security Prices (CRSP) at the University of Chicago, and are obtained by grouping all stocks listed at the New York Stock Exchange (NYSE). In addition, we use return data on the CRSP value weighted index, with and without dividends, and the CRSP equally weighted index with and without dividends. The riskless return is approximated by the monthly return on a 3 month U.S. Treasury Bill. These data are essentially the same as used in Cochrane (1996). We also have the following data: a consumption price index, personal consumption expenditures on nondurables and services, and industrial production. Summary statistics for most of these variables are given in Table A1 in the appendix. The Treasury Bill return has a low mean and does not vary much over time. The returns on stocks have a substantially higher mean and are much more volatile. The size-based portfolio returns are ranked according to their market capitalization" ${ }^{9}$ the first portfolio contains "small" firms, the tenth portfolio contains "large" firms. To illustrate the differences in returns from the different portfolios, Figure 1 presents the nominal yield on four of the ten decile portfolios and on the Treasury Bill on a hypothetical investment of 100 dollar in $1959 .^{10}$ After 35 years, the yield on the portfolio with low market capitalization is the highest. The yield of the portfolio with the "largest" firms is the lowest of the ten portfolios. While for the sake of visibility we only plot four of the ten risky portfolio, the lines for the other portfolios would be located between the extremes of portfolio 1 and 10. Small firms have on average higher retuns because they are more volatile than large firms. This effect is particularly extreme in January (probably due to tax loss selling). As a benchmark we also look at the yield on Treasury Bills, which is surprisingly low compared to the yields of the portfolios. Note that the October 1987 crash and the fall in prices in 1990 and 1991 (recession and Gulf war) are easily recognized in Figure 1.

To obtain the ex dividend returns $\left(p_{t+1}^{i} / p_{t}^{i}\right)$ for the decile portfolios (indexed by $i$ ) we

\footnotetext{
${ }^{9}$ Market capitalization is defined as the product of the price of the share and the number of shares outstanding.

${ }^{10}$ In this paper we neglect the potential influence of survivorship bias (see, for example, Brown, Goetzmann and Ross, 1995).
} 
use the following proxy: $\left(p_{t+1}^{i}+d_{t+1}^{i}\right) / p_{t}^{i}-d_{t+1} / p_{t}$, which is the gross return for decile $i$ minus the dividend-price ratio for the market return. The NYSE turnover rates, which we use for $\Omega_{t}$, are determined as the ratio of the total number of shares traded and the total number of shares outstanding. The number of shares traded is obtained from daily observations from the NYSE. This resulting series is plotted in Figure 2.

The equity premium, i.e. the average excess return on the stock market, can easily be calculated from the numbers in Table A1. For the period 1959-1993, the average annual real return on stocks is 6.61 percent. On the short-term Treasury Bill, this return is about 1.28 percent, so that the mean equity premium over this period is 5.33 percent. Mehra and Prescott (1985) have argued that this equity premium is too high to be explained by the standard asset pricing models.

\subsection{Estimation results}

In Section 2 we derived the first order conditions of the intertemporal asset pricing model with transaction costs, and Section 3 discussed the GMM techniques that can be used to estimate and test the model. To this end, we need to specify a functional form for the utility function and we shall start by assuming a power utility specification, $u\left(c_{t}\right)=$ $\frac{1}{1-\gamma} c_{t}^{1-\gamma}$, which is the most common choice in this area of research. It is characterized by a constant coefficient of relative risk aversion $\gamma$. Later, more complex utility functions will be examined. Substitution into (11) and (7) results in:

$$
\begin{gathered}
E_{t}\left\{\delta\left(\frac{c_{t+1}}{c_{t}}\right)^{-\gamma}\left[\frac{1}{1+\alpha} r_{t+1}^{i}+\frac{\alpha}{1+\alpha}\left(1-2 \Omega_{t+1}\right) \frac{p_{t+1}^{i}}{p_{t}^{i}}\right]\right\}=1, \\
E_{t}\left\{\delta\left(\frac{c_{t+1}}{c_{t}}\right)^{-\gamma} \frac{1}{p_{t}^{b}}\right\}=1,
\end{gathered}
$$

for $i=1, \ldots, 10$.

We use real per capita expenditures on consumer nondurable goods and services as measure for consumption, where all consumption and return series have been adjusted for inflation. We also experimented with industrial production data as measure of consumption (like Fisher, 1994), but the performance of the model based on this measure was substantially worse. Empirical results for the model with and without transaction costs, obtained from the iterated and one-step GMM estimators are reported in Table 1.

The estimates look rather poor. For all specifications, the estimated time preference parameter $\delta$ is lower than expected, while the estimated risk aversion coefficient is extremely 
Table 1: GMM estimation results of model with transaction costs, 1959-1993.

\begin{tabular}{lcccccc}
\hline \hline & $\delta$ & $\gamma$ & $\alpha$ & $J_{T}$ & DF & $T$ \\
\hline Iterated GMM & 0.8337 & 56.9363 & - & 5.6923 & 9 & 418 \\
& $(0.1163)$ & $(34.2604)$ & - & & & \\
1-step GMM & 0.7025 & 91.6393 & - & 4.3846 & 9 & 418 \\
& $(0.1438)$ & $(38.1066)$ & - & & & \\
Iterated GMM & 0.8290 & 58.2694 & -0.0022 & 6.4528 & 8 & 418 \\
& $(0.2085)$ & $(59.4491)$ & $(0.0761)$ & & & \\
1-step GMM & 0.5611 & 125.465 & -0.0584 & 5.4732 & 8 & 418 \\
& $(0.3154)$ & $(89.8519)$ & $(0.1113)$ & & & \\
\hline Model includes ten size-based portfolios of risky stocks and a riskless asset. \\
Standard errors in parentheses.
\end{tabular}

high. Such extreme values for $\gamma$ are considered implausible and reflect the equity premium puzzle. Similar results are found elsewhere in the literature (see, for example, Cochrane (1996), and Ferson and Constantinides (1991)). Note that the corresponding standard errors are also high. As a result we can not, for example, reject the null hypotheses that the time preference parameter equals one, or for the specification with transaction costs, that the relative risk aversion coefficient equals zero. The estimated value of the transaction costs parameter has the wrong sign, but does not differ significantly from zero. If the transaction costs $\alpha$ are set to zero, the estimates for $\gamma$ are still very high, although they are somewhat more precisely estimated. While the reported standard errors, based upon the asymptotic covariance matrix, are smaller for the iterated GMM estimator than for the one-step estimator, there are results (see, for example, Kocherlakota (1990)) that suggest that the asymptotic approximations are inaccurate and that standard errors are substantially underestimated.

To evaluate the different specifications we use the overidentifying restrictions tests and plots of pricing errors. The column headed $J_{T}$ presents the values of the overidentifying restrictions test statistics, which have, under the null, a $\chi^{2}$ distribution. The corresponding degrees of freedom (DF) are given in the next column and equal the number of moment conditions minus the number of parameters to be estimated. For both estimators and both specifications the model is not rejected at the $5 \%$ significance level. This is probably due to the very high standard errors. ${ }^{11}$

\footnotetext{
${ }^{11}$ Note that the overidentifying restrictions test has more power when including instrumental variables.
} 
Figure 3: Pricing error plot of model with transaction costs estimated by iterated GMM.

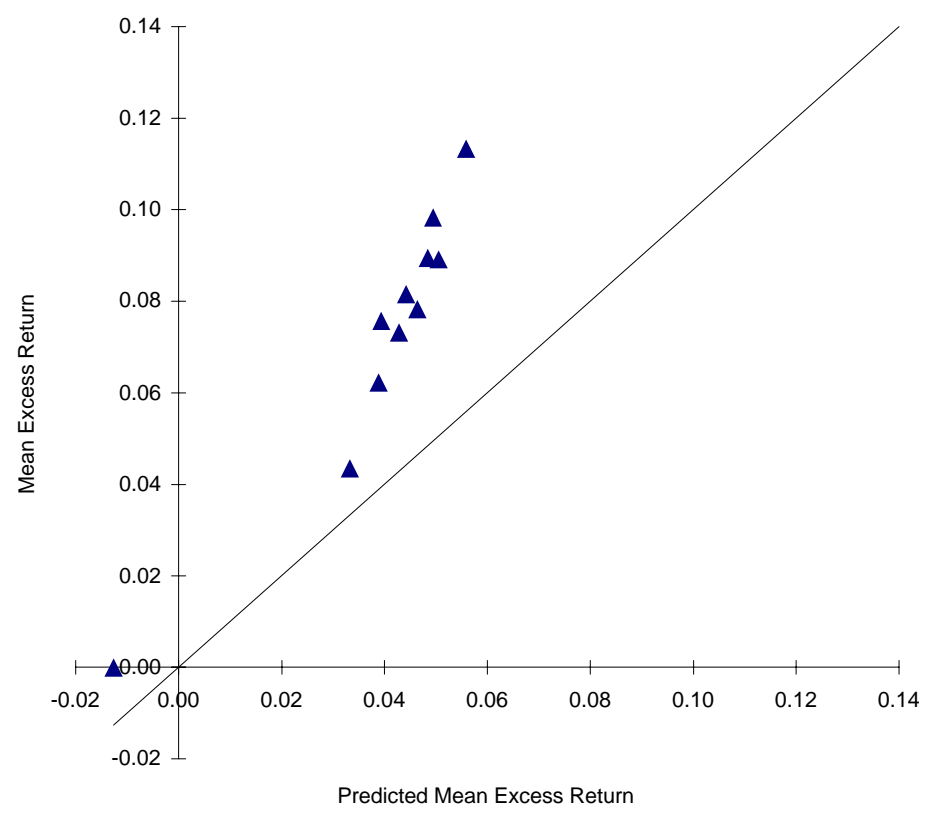

Figure 4: Pricing error plot of model with transaction costs estimated by one-step GMM.

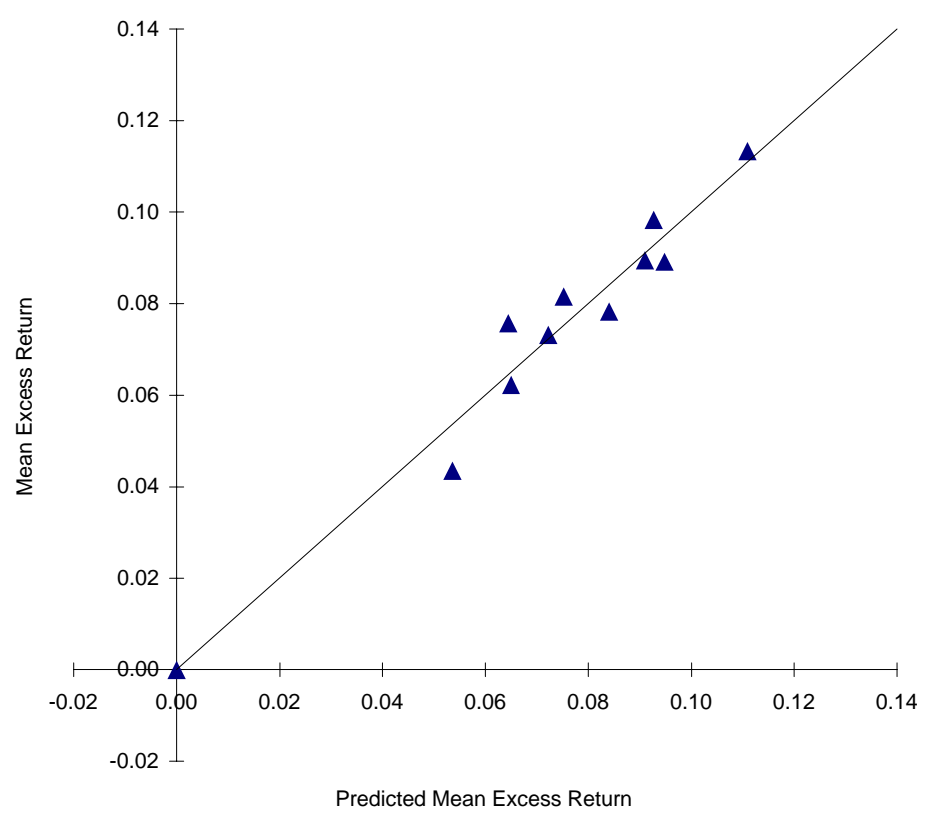


Figure 3 and 4 present the pricing error plots of the model with transaction costs estimated by iterated and one-step GMM. The mean excess returns on the ten size-based portfolio and the riskless asset, as reported in Table A1, are plotted on the vertical axis, while the horizontal axis gives the values of the predicted mean excess returns determined from the estimated model using formula (16).

The argument given in Section 3, that iterated GMM uses a weighting matrix which may give a high weight to (combinations of) statistically well-measured but economically uninteresting moment conditions, seems to arise in this situation. The pricing errors in Figure 3 look much worse than those in Figure 4. The closer the triangles to the 45degree line, the better the predictions, the smaller the pricing errors. The upper triangle corresponds with the portfolio of small firms. This particular portfolio has the largest pricing error in Figure 3, but is very well priced according to Figure 4. The lower triangle represents the Treasury Bill, which, by definition, has a mean excess return of zero. Note that in Figure 3 all triangles are at the left side of the 45-degree line, which indicates that the model estimated by iterated GMM underpredicts the excess returns on all assets. This in contrast with Figure 4 where the triangles do not deviate much from the 45-degree line. Apparently, estimating the model by one-step GMM leads to subtiantially more accurate predictions. Note that excluding transaction costs results in pricing error plots in which the predictions are substantially worse.

We conclude that the iterated GMM generates much larger pricing errors than the one-step GMM. Both versions generate unrealistic estimates with high standard errors, which indicates that the model is not correctly specified. It appears that the inclusion of transaction costs alone is not sufficient to solve the equity premium puzzle. In the next section we shall examine whether the inclusion of habit persistence leads to more realistic estimates.

\section{Introducing Habit Persistence}

Using the Hansen-Jagannathan volatility bounds, Gallant et al. (1990), Cochrane and Hansen (1992) and Luttmer (1996) show that habit persistence reduces the required risk aversion coefficient. The higher the degree of habit persistence, the larger the volatility of the stochastic discount factor. In this section we look at the effects of relaxing the assumption of a time separable utility function by introducing habit persistence.

We use a particular specification of habit persistence, as in Ferson and Constantinides 
(1991), Cochrane and Hansen (1992), Heaton (1995) and Kocherlakota (1996), in which the utility function at time $t$ depends on $c_{t}$ and $c_{t-1}$, namely $u\left(c_{t}, c_{t-1}\right)=\frac{1}{1-\gamma}\left(c_{t}-\right.$ $\left.\theta c_{t-1}\right)^{1-\gamma}$, where $\theta$ is the degree of habit persistence. The idea behind this extension is that consumers get used to high levels of consumption and desire a high consumption in period $t$, when consumption in period $t-1$ was high. Note that the utility function in the maximization problem, $u\left(c_{t+j}\right)$, should be replaced with $u\left(c_{t+j}, c_{t+j-1}\right)$. This implies the following marginal utility with respect to period $t$ consumption:

$$
\left(c_{t}-\theta c_{t-1}\right)^{-\gamma}-\delta \theta E_{t}\left\{\left(c_{t+1}-\theta c_{t}\right)^{-\gamma}\right\},
$$

The first term in (20) basically says that if I consume today more than my consumption of yesterday times a habit persistence parameter, I will acquire additional utility, while the second term implies that having a high consumption today wants to make you have a high consumption in the future, it reduces utility from future consumption. From (20) we obtain the following stochastic discount factor (see also Cochrane and Hansen (1992) and Kocherlakota (1996)):

$$
m_{t+1}=\delta\left(\frac{c_{t+1}}{c_{t}}\right)^{-\gamma} \frac{\left(1-\theta \frac{c_{t}}{c_{t+1}}\right)^{-\gamma}-\delta \theta E_{t+1}\left\{\left(\frac{c_{t+2}}{c_{t+1}}-\theta\right)^{-\gamma}\right\}}{\left(1-\theta \frac{c_{t+1}}{c_{t}}\right)^{-\gamma}-\delta \theta E_{t}\left\{\left(\frac{c_{t+1}}{c_{t}}-\theta\right)^{-\gamma}\right\}} .
$$

Note that when $\theta=0$, we obtain the original CRRA Euler equation. When $\theta$ is positive, consumption goods are complementary over time and preferences exhibit habit persistence. When $\theta$ is negative, consumption goods are substitutable among adjacent periods, which is sometimes referred to as durability in consumption (expenditures). We estimate this specification of the model by both one-step GMM and iterated GMM. Following Cochrane and Hansen (1992) and Kocherlakota (1996), we approximate the conditional expectations in (21) by the sample means, which can be justified if consumption growth can be described by a random walk. Table 2 reports the estimation results for the model with and without transaction costs as specified in (5).

The estimated time preference parameter is larger than one, but not significantly. The drop in the estimate of $\gamma$ is huge in both cases. Note that in this specification the curvature parameter $\gamma$ is no longer equal to the coefficient of relative risk aversion. The average RRA coefficient can be computed as $R R A=\gamma(T-1)^{-1} \sum_{t=1}^{T-1} c_{t} /\left(c_{t}-\theta c_{t-1}\right)$ and the resulting values as given in Table 2. Ranging from 0.9916 to 4.3446 , these numbers are much more realistic than the estimated RRA coefficients in Section 4 for the model without habit persistence. This result suggests that time-nonseparable utility is a plausible explanation 
Table 2: GMM estimation results of model with transaction costs and habit persistence, 1959-1993.

\begin{tabular}{lcccccccc}
\hline \hline & $\delta$ & $\gamma$ & $\theta$ & $\alpha$ & $\mathrm{RRA}$ & $\mathrm{J}_{T}$ & $\mathrm{DF}$ & $\mathrm{T}$ \\
\hline Iterated GMM & 1.0073 & 0.0419 & 0.9705 & - & 1.5442 & 5.1152 & 8 & 418 \\
& $(0.0260)$ & $(0.0840)$ & $(0.0179)$ & - & & & & \\
1-step GMM & 1.0121 & 0.0270 & 0.9738 & - & 0.9916 & 3.8134 & 8 & 418 \\
& $(0.0832)$ & $(0.1634)$ & $(0.0002)$ & - & & & & \\
Iterated GMM & 1.0078 & 0.0709 & 0.9629 & 0.0290 & 2.1718 & 4.7103 & 7 & 418 \\
& $(0.0287)$ & $(0.3515)$ & $(0.0760)$ & $(0.0524)$ & & & & \\
1-step GMM & 1.0203 & 0.2580 & 0.9419 & 0.0487 & 4.3446 & 2.7858 & 7 & 418 \\
& $(0.0722)$ & $(0.1526)$ & $(0.0002)$ & $(0.1197)$ & & & & \\
\hline
\end{tabular}

Model includes ten size-based portfolios of risky stocks and a riskless asset.

Standard errors in parentheses.

for the equity premium puzzle. ${ }^{12}$ The point estimates of the nonseparability parameter $\theta$ are close to one and significantly different from zero, which can be interpreted as evidence that habit persistence in consumption plays an important role. If the habit persistence parameter $\theta$ equals one, this means that mainly differences in consumption matter rather than levels. Although this situation seems somewhat extreme, it is in line with other studies (see, for example, Ferson and Constantinides (1991)). Using survey data on individual wage satisfaction, Clark (1996) estimates habit formation in annual wages with results that imply values for $\theta$ around 0.92 . Note that in general monthly data produce relatively high values of $\theta$, while lower frequency data yield smaller estimates of $\theta$. Looking at the one-step GMM estimator for the model with transaction costs, the estimated transaction cost parameter is 0.05 , so that the estimated bid-ask spread is 0.10 . Unfortunately, the corresponding standard error is quite high and the estimate is not very accurate. One reason for this result is the fact that $\delta$ is empirically not very well identified and this carries over to the other model parameters. If we would fix $\delta$ at a value slightly smaller

\footnotetext{
${ }^{12}$ As He and Modest (1995) and Heaton (1995), we checked whether the model satisfies the volatility bounds (Hansen and Jagannathan, 1991) in the following way. Like He and Modest (1995) we use a time preference parameter of 0.99754 , which corresponds to an annual time preference parameter of 0.97 . The IMRS's corresponding to $\theta=0$ enter the region when $\gamma>190$. While negative values of $\theta$ makes the required $\gamma$ even higher, positive values of $\theta$ lowers the required value of $\gamma$. When, for example, $\theta=0.8$, the IMRS's approach the bound for values of $\gamma$ between 0 and 1 . There are no major shifts of the volatility bounds when transaction costs are involved.
} 
than one, as is done by Fisher (1994), the estimate for the transaction cost component has the same order of magnitude, but the estimate of the transaction costs parameter becomes statistically different from zero. Note that our estimate of the transaction costs parameter is considerable lower than found by Fisher (1994), whose estimates, using annual data from 1942 to 1985 , range between 0.096 and 0.121 .

Compared to the results for the model without habit persistence presented in Table 1, the estimates found here are much more realistic and the standard errors are much smaller. Again, the overidentifying restrictions test do not suggest any misspecification at the 5 percent significance level, while the test statistics have slightly smaller values than those reported in Table 1. The main issue is whether the model does a good job in explaining the cross-sectional variation in returns and we analyze this question by considering pricing error plots, as before. Figure 5 presents the pricing errors for the model with habit persistence, but without transaction costs and indicates that this model performs reasonably well in predicting the average excess returns. The plot of the pricing errors for the model with transaction costs is given in Figure 6 and shows that the excess returns of the ten sizebased portfolios are predicted very well in this situation. All triangles are very close to the 45-degree line. Comparing all pricing error plots, it is clear that the model with both transaction costs and habit persistence estimated by one-step GMM generates the smallest pricing errors.

In all specifications above we have assumed symmetrical transaction costs. To analyze the effects of relaxing this assumption, we assumed instead that stocks are bought at $p_{t}(1+\alpha)$ and sold at $p_{t}(1-\beta)$ at time $t$, which results in a bid-ask spread of $[-\beta, \alpha]$. Allowing for these asymmetrical transaction costs leads to almost identical point estimates for $\alpha$ and $\beta$ and we can not reject the hypothesis that $\alpha$ does not differ significantly from $\beta$. We also experimented with varying transaction costs for the size-based portfolios. It may well be possible that these costs are higher for small stocks, because it is often harder to obtain information about small firms. Another reason is that investing in small stocks has relatively more market impact. In general the estimates we found for the smaller sizebased portfolios are a bit higher than those from the larger size-based portfolios, but the differences were not significant. 
Figure 5: Pricing error plot of model with habit persistence estimated by one-step GMM.

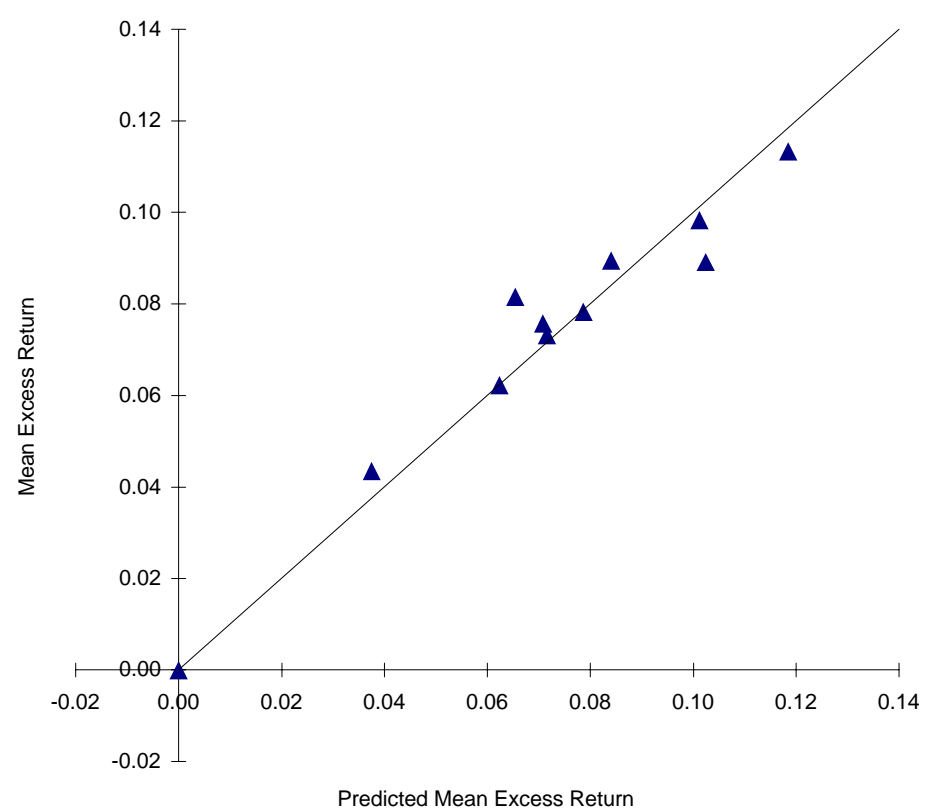

Figure 6: Pricing error plot of model with habit persistence and transaction costs estimated by one-step GMM.

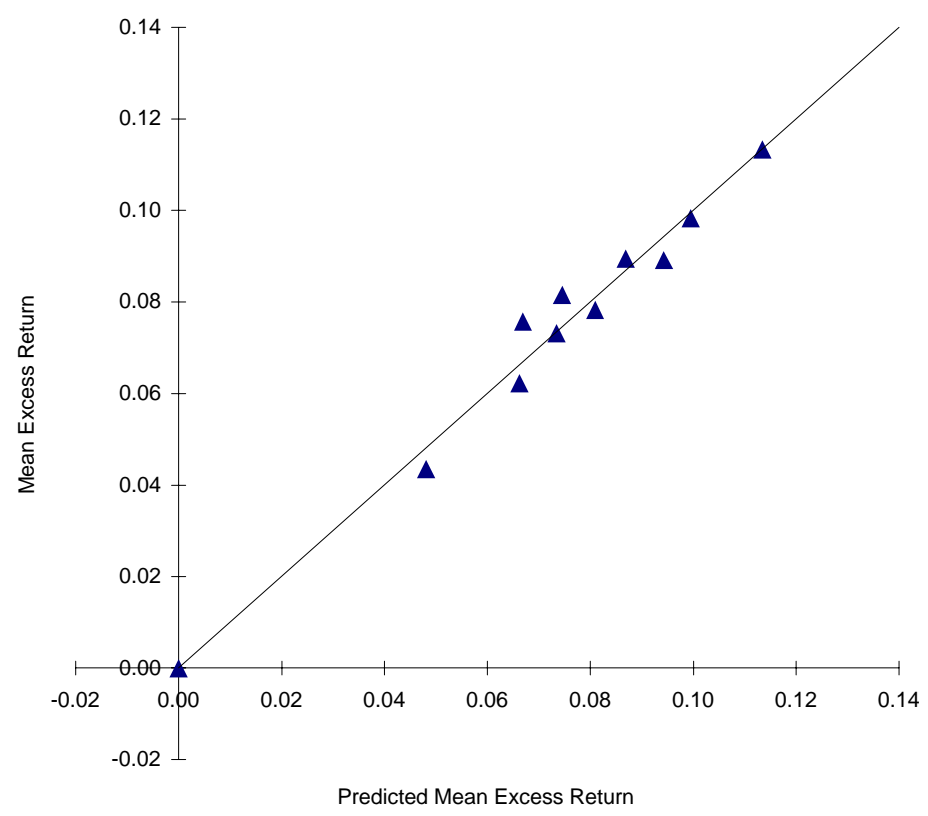




\section{Concluding Remarks}

In this paper, we developed a consumption-based asset pricing model in the presence of transaction costs in the stock market and habit persistence in consumption and estimated this model using monthly returns on ten size-based portfolios and a riskless return over the period 1959-1993. Our main goal was to analyze to what extent the introduction of transaction costs was able to explain the cross-sectional variation in expected returns. All models were estimated using both iterated and one-step GMM and plots of the models' pricing errors revealed that one-step GMM estimates do a much better job in capturing the variation in expected excess returns. For the consumption-based model with power utility, the introduction of transaction costs improves the predictions of the model, but the parameter estimates are economically implausible and have high standard errors. Next we relaxed the assumption of a time-separable additive utility function and introduced habit persistence in the model. This extension, combined with transaction costs, appeared profitable. Although the standard errors are still relatively high, the parameter estimates were much more realistic and the pricing errors were fairly small. The monthly mean excess returns on the ten size-based portfolios are predicted well within the sample, and tests of the overidentifying restrictions of the model did not reject. The estimated degree of habit persistence in monthly consumption is high, but in line with other results from the literature. The combination of habit persistence and transaction costs yielded the most satisfactory results, thus providing a potential answer to the equity premium puzzle.

Appendix: Univariate Statistics

Table A1: Univariate statistics, monthly frequency, sample 1959(2) - 1993(10) 


\begin{tabular}{llccc}
\hline \hline & Mean & Std Dev & Minimum & Maximum \\
\hline Value weighted return & 1.00923 & 0.04280 & 0.78382 & 1.16832 \\
Treasury Bill return $r^{f}$ & 1.00494 & 0.00220 & 1.00185 & 1.01266 \\
Excess return portfolio 1 & 0.00899 & 0.07029 & -0.30557 & 0.57353 \\
Excess return portfolio 2 & 0.00784 & 0.06163 & -0.30801 & 0.42680 \\
Excess return portfolio 3 & 0.00714 & 0.05851 & -0.29946 & 0.36794 \\
Excess return portfolio 4 & 0.00717 & 0.05577 & -0.28881 & 0.30234 \\
Excess return portfolio 5 & 0.00630 & 0.05344 & -0.28535 & 0.25421 \\
Excess return portfolio 6 & 0.00656 & 0.05194 & -0.28207 & 0.25353 \\
Excess return portfolio 7 & 0.00591 & 0.05038 & -0.26206 & 0.22488 \\
Excess return portfolio 8 & 0.00610 & 0.04907 & -0.26610 & 0.21334 \\
Excess return portfolio 9 & 0.00505 & 0.04638 & -0.23000 & 0.17015 \\
Excess return portfolio 10 & 0.00355 & 0.04144 & -0.20057 & 0.17492 \\
Turnover rate $\Omega$ & 0.02599 & 0.01370 & 0.00759 & 0.06668 \\
Inflation & 0.00388 & 0.00323 & -0.00547 & 0.01810 \\
Consumption growth & 1.00159 & 0.00389 & 0.98916 & 1.01612 \\
\hline
\end{tabular}




\section{References}

[1] Abel, A.B. (1990), "Asset Prices under Habit Formation and Catching Up with the Joneses", American Economic Review, 80, 38-42.

[2] Amihud, Y., and H. Mendelson (1986), "Asset Pricing and the Bid-Ask Spread", Journal of Financial Economics, 15, 223-249.

[3] Amihud, Y., and H. Mendelson (1989), "The Effects of Beta, Bid-Ask Spread, Residual Risk, and Size on Stock Returns", Journal of Finance, 19, 479-486.

[4] Brown, S., and M. Gibbons (1985), "A Simple Econometric Approach for Testing Utility Based Asset Pricing Models", Journal of Financial Economics, 359-381.

[5] Brown, S., W.N. Goetzmann, and S.A. Ross (1995), "Survival", Journal of Finance, $50,853-874$.

[6] Campbell, J.Y., A.W. Lo, and A.C. MacKinlay (1997), "The Econometrics of Financial Markets", Princeton University Press, Princeton, New Jersy.

[7] Clark, A.E. (1996), "Are Wages Habit-Forming? Evidence from Micro Data", DEELSA, OESO, Paris.

[8] Cochrane, J.H., (1996), " A Cross-Sectional Test of an Investment-Based Asset Pricing Model", Journal of Political Economy, 104, 3, 572-621.

[9] Cochrane, J.H., and L.P. Hansen, (1992), "Asset Pricing Explorations for Macroeconomics", in NBER Macroeconomics Annual 1992, Massachusettes Insitute of Technology Press, Cambridge, MA, 115-165.

[10] Ferson, W., and G. Constantinides (1991), "Habit Persistence and Durability in Aggregate Consumption", Journal of Financial Economics, 29, 199-240.

[11] Ferson, W., and S. Foerster (1994), "Finite Sample Properties of the Generalized Method of Moments in Tests of Conditional Asset Pricing Models: Empirical Tests", Journal of Financial Economics, 36, 29-55.

[12] Fisher, S.J. (1994), "Asset Trading, Transaction Costs and the Equity Premium", Journal of Applied Econometrics, 9, S71-S94. 
[13] Gallant, A.R., L.P. Hansen, and G. Tauchen (1990), "Using Conditional Moments of Asset Payoffs to Infer the Volitility of Intertemporal Marginal Rates of Substitution", Journal of Econometrics, 45, 141-179.

[14] Hansen, L.P. (1982), "Large Sample Properties of Generalized Method of Moments Estimators", Econometrica, 50, 1029-1054.

[15] Hansen, L.P., J. Heaton, and E.G.J. Luttmer (1995), "Econometric Evaluation of Asset Pricing Models", Review of Financial Studies, 8,2, 237-274.

[16] Hansen, L.P., and K.J. Singleton (1982), "Generalized Instrumental Variables Estimation of Nonlinear Rational Expectations Models", Econometrica, 50, 1269-1286.

[17] Hansen, L.P., and R. Jagannathan (1991), "Implications of Security Market Data for Models of Dynamic Economies", Journal of Political Economy, 99, 225-262.

[18] He, H., and D.M. Modest (1995), "Market Frictions and Consumption-Based Asset Pricing", Journal of Political Economy, 103, 1, 94-117.

[19] Heaton, J. (1995), "An Empirical Investigation of Asset Pricing with Temporally Dependent Preference Specifications", Econometrica, 63, 3, 681-717.

[20] Heaton, J., and D.J. Lucas (1996), "Evaluating the Effects of Incomplete Markets on Risk Sharing and Asset Pricing", Journal of Political Economy, 104, 3, 443-487.

[21] Kocherlakota, N.R. (1990), "On Tests of Representative Consumer Asset Pricing Models", Journal of Monetary Economy, 26, 285-304.

[22] Kocherlakota, N.R. (1996),"The Equity Premium: It's Still a Puzzle", Journal of Economic Literature, vol 34, 42-71.

[23] Luttmer, E.G.J. (1996), "Asset Pricing in Economies with Frictions", Econometrica, $64,6,1439-1467$.

[24] Mehra, R., and E.C. Prescott (1985), "The Equity Premium: A Puzzle", Journal of Monetary Economy, 15, 145-161.

[25] Rubinstein, M. (1974), "An Aggregation Theorem for Securities Markets", Journal of Financial Economics, 225-244. 
[26] Schultz, P. (1983), "Transaction Costs and the Small Firm Effect, A Comment", Journal of Financial Economics, 81-88.

[27] Singleton, K.J. (1990), "Specification and Estimation of Intertemporal Asset Pricing Models", Chapter 12 in Handbook of Monetary Economics, vol. I, edited by B.M. Friedman and F.H. Hahn, 583-626.

[28] Singleton, K.J. (1994), "Econometric Analysis of Representative Agent Intertemporal Asset Pricing Models", in Sims, C., ed., Advances in Econometrics. Sixths World Congress, Vol II, Cambridge Press. 


\section{DISCUSSION PAPERS 1997}

DPS 97.01 Hans Dewachter, Geert Gielens and Dirk Veestraeten, An Assessment of Central Banks.' Stand on Exchange Rate Stabilization Policies, February. (International Economics).

DPS 97.02 Anneleen Peeters, How Hiring and Firing Costs Affect Labour Demand in a Model of Uncertainty, February. (International Economics).

DPS 97.03 Hans Eyssen, Are West-African Immigrants Discriminated in Cote DIvoire?, March. (Development Economics).

DPS 97.04 Wim Lagae, The Absorption of the Effects of Debt Relief Operations by European Export Credit Agencies: An Institutional Analysis, March. (Development Economics).

DPS 97.05 Jenke ter Horst and Marno Verbeek, Estimating Short-Run Persistence in Mutual Fund Performance, March. (Econometrics).

DPS 97.06 Hans Dewachter and Hanno Lustig, A Cross-Country Comparison of CPI as a Measure of Inflation, April. (Financial Economics).

DPS 97.07 Yunus Aksoy and Yohanes E. Riyanto, Exchange Rate Pass-Through in Vertically Related Markets, May. (International Economics).

DPS 97.08 Paul De Grauwe, The Indeterminacy of the Euro Conversion Rates. Why it Matters and how it can be solved, June. (International Economics).

DPS 97.09 Jozef Konings, Hylke Vandenbussche and Reinhilde Veugelers, Union Wage Bargaining and European Antidumping Policy, June (Financial Economics).

DPS 97.10 Francis Vella and Marno Verbeek, Using Rank Order as an Instrumental Variable: An Application to the Return to Schooling, May. (Econometrics).

DPS 97.11 Jozef Konings and Patrick P. Walsh, The Effect of Real Exchange Rate Movements and Ownership on the Life Cycle of Manufacturing Plants in Ireland (1973-1994), June. (Financial Economics).

DPS 97.12 Johan Eyckmans, Balancedness of games with multilateral environmental externalities, August. (Public Economics).

DPS 97.13 Patrick Van Cayseele and Dave FURTH, Price Leadership and Buyouts, September. (Financial Economics).

DPS 97.14 Mark De Broeck, Dominique Guillaume and Emmanuel Van der Stichele, Small and Big Bangs in Bond Markets, September (Financial Economics).

DPS 97.15 Hanno Lustig, Re-examining the Synchronization of European Business Cycles, September (Financial Economics).

DPS 97.16 Jõ̃ P. Cocco, Francisco J. Gomes and Pascal J. Maenhout, A Two-Period Model of Consumption and Portfolio Choice With Incomplete Markets, June (Financial Economics). 
DPS 97.17 Stefan Dercon and Daniel Ayalew, Demobilisation and Reintegration of ExSoldiers in Ehtiopia, October (Development Economics).

DPS 97.18 Stefan Dercon and Pramila Krishnan, In Sickness and in HealthRisk-Sharing within Households in Rural Ethiopia, October (Development Economics).

DPS 97.19 Paul Collier, Stefan Dercon and John Mackinnon, Density versus Quality in Health Care Provision: The Use of Household Data for Budgetary Choices in Ehtiopia October (Development Economics).

DPS 97.20 van der Lijn Nick and Marno Verbeek, Excess demand, repressed inflation, and forced saving in the Soviet Union, October (Econometrics).

DPS 97.21 Lorelei Crisologo-Mendoza and Dirk Van de gaer, Population Growth and Customary Law on Land: The Case of Cordillera Villages in the Philippines, October (Development Economics).

DPS 97.22 Tom Van Puyenbroeck, Two-stage optimal control problems subject to an isoperimetric constraint, October (Public Economics).

DPS 97.23 Erik Schokkaert, Geert Dhaene and Carine Van de Voorde, Risk Adjustment and the Trade-off Between Efficiency and Risk Selection, November (Public Economics).

DPS 97.24 Paul De Grauwe, Hans Dewachter and Dirk Veestraeten, Stochastic Process Switching and Stage III of EMU, November (International Economics).

DPS 97.25 Dirk Heremans, Regulation of Banking and Financial Intermediation, November (Financial Economics).

DPS 97.26 Knud J. Munk, Agricultural Policy a Public Economic Explanation, November (Public Economics).

DPS 97.27 Hans Dewachter, Can Markov Switching Models Replicate Chartist Profits in the Foreign Exchange Market? November (International Economics).

DPS 97.28 Paul De Grauwe and Frauke Skudelny, The Impact of EMU on Trade Flows, December (International Economics). 


\section{DISCUSSION PAPERS 1998}

DPS 98.01 Louis Baeck, Thematisation and Canon Building in Post-War Development Studies, January (Development Economics).

DPS 98.02 Hans Dewachter and Hanno Lustig, Sticky Prices and the Nominal Effects of Real Shocks, January (International Economics).

DPS 98.03 Ilse Frederickx, Health in Rural Tanzania: The Determinants of Health Status, Health Care Demand and Health Care Choice, January (Development Economics).

DPS 98.04 Paul De Grauwe, European Unemployment. A Tale of Demand and Supply, February (International Economics).

DPS 98.05 Jo旡 Cocco, Francisco Gomes and Pascal Maenhout, Consumption and Portfolio Choice over the Life-Cycle, March (Financial Economics).

DPS 98.06 Yunus Aksoy and Hanno Lustig, Circular Aspects of Exchange Rates and Market Structure, January (International Economics).

DPS 98.07 André Decoster and Frederic Vermeulen, Evaluation of the Empirical Performance of Two-Stage Budgeting AIDS, QUAIDS and Rotterdam Models Based on Weak Separability, April (Public Economics).

DPS 98.08 Erik Schokkaert and Luc Van Ootegem, Preference Variation and Private Donations, April (Public Economics).

DPS 98.09 Erik Schokkaert, Mr. Fairmind is Post-Welfarist: Opinions on Distributive Justice, April (Public Economics).

DPS 98.10 Dirk Van de gaer, Michel Martinez and Erik Schokkaert, Measuring Intergenerational Mobility and Equality of Opportunity, April (Public Economics).

DPS 98.11 Paulo Augusto Nunes, Testing the Validity of WTP values from a Contingent Valuation Survey in Portugal, April (Public Economics).

DPS 98.12 Paulo Augusto Nunes, Measuring the WTP for Recreation and Biodiversity Protection Programs, April (Public Economics).

DPS 98.13 Laurens Cherchye and Tom Van Puyenbroeck, Learning from Input-Output Mixes in DEA: A Proportional Measure for Slack-Based Efficient Projections, February (Public Economics).

DPS 98.14 Jerzy Mycielski and Yohanes Riyanto, On the Interaction between Taste and Distance and Its Implications on the Vertical Distribution Arrangement, May (Financial Economics).

DPS 98.15 Jerzy Mycielski, Yohanes Riyanto and Filip Wuyts, Product Differentiation and the Equilibrium Structure of the Manufacturer-Retailer Relationship, May (Financial Economics). 
DPS 98.16 Hans Degryse and Patrick Van Cayseele, Relationship Lending within a Bankbased System: Evidence from European Small Business Data, April (Financial Economics).

DPS 98.17 Pramila Krishnan, Tesfaye Gebre Selassie and Stefan Dercon, The Urban Labour Market During Structural Adjustment: Ethiopia 1990-1997, April (Development Economics).

DPS 98.18 Bart Capáu and Stefan Dercon, Prices, Local Measurement Units and Subsistence Consumption in Rural Surveys: An Econometric Approach with an Application to Ethiopia, March (Development Economics).

DPS 98.19 Stefan Dercon and Pramila Krishnan, Changes in Poverty in Rural Ethiopia 1989-1995: Measurement, Robustness Tests and Decomposition, March (Development Economics).

DPS 98.20 Jenke R. ter Horst, Theo E. Nijman and Marno Verbeek, Eliminating Biases in Evaluating Mutual Fund Performance from a Survivorship Free Sample, June (Econometrics).

DPS 98.21 Hilke Vandenbussche and Jozef Konings, Globalization and the effects of national versus international competition on the labour market. Theory and evidence from Belgian firm level data, August (Financial Economics).

DPS 98.22 Wim Moesen and Laurens Cherchye, The Macroeconomic Performance of Nations Measurement and Perception, August (Public Economics).

DPS 98.23 Anneleen Peeters, Interim Employment and a Leading Indicator for the Belgian Labour Market, September (International Economics, IERP 137).

DPS 98.24 Wessel Marquering and Marno Verbeek, An Empirical Analysis of Intertemporal Asset Pricing Models with Transaction Costs and Habit Persistence, September (Econometrics).

DPS 98.25 Filip Abraham and Joeri Van Rompuy, Is Belgium ready for EMU? A look at national, sectoral and regional developments, September (International Economics, IERP 138).

DPS 98.26 Sara Ochelen, Stef Proost and Kurt Van Dender, Optimal Pricing for Urban Road Transport Externalities, September (Public Economics).

DPS 98.27 Knud Munk, Optimal Support to Low-skilled Households, July (Public Economics).

DPS 98.28 Wim Moesen and Philippe Van Cauwenberge, The Status of the Budget Constraint, Federalism and the Relative Size of Government: A Bureaucracy Approach, September (Public Economics).

DPS 98.29 Laurens Cherchye, The Measurement of Macroeconomic Performance: Comparison of DEA-Based Alternatives, August (Public Economics).

DPS 98.30 Jïgen Janssens, Volatility and Risk Premia on Belgian Secondary Long Term Government Bond Markets, October (Financial Economics). 
DPS 98.31 Stef Proost and Kurt Van Dender, Effectiveness and Welfare Impacts of Alternative Policies to Address Atmospheric Pollution in Urban Road Transport (Public Economics).

DPS 98.32 Inge Mayeres and Stef Proost, Marginal Tax Reform, Externalities and Income Distribution (Public Economics). 